\title{
O acesso à educação especial em Marabá-Pará: análise do indicador "matrícula escolar", no período de 2015 a 2017
}

\author{
Access to special education in Marabá-Pará: analysis of the "school \\ enrollment" indicator, from 2015 to 2017
}

Acceso a educación especial en Marabá-Pará: análisis del indicador "matrícula escolar", de 2015 a 2017

\author{
Mírian Rosa Pereira \\ Professora mestra na Universidade do Estado do Pará, Marabá, Pará, Brasil. \\ mirian-pereira@hotmail.com \\ ORCID - http://orcid.org/0000-0002-8157-1192 \\ Maria Edilene da Silva Ribeiro \\ Professora doutora na Universidade do Estado do Pará, Belém, Pará, Brasil. \\ mariaedileneribeiro@yahoo.com.br \\ ORCID - http://orcid.org/0000-0001-8605-9406
}

Recebido em 4 de julho 2019

Aprovado em 17 de agosto de 2020

Publicado em 30 de setembro de 2020

\section{RESUMO}

Este artigo discorre sobre a inclusão escolar das pessoas com deficiência em meio ao contexto da reforma do Estado brasileiro e das contradições do sistema capitalista, com o foco do estudo centrado no acesso à educação especial no município de Marabá, estado do Pará. O objetivo geral é analisar o acesso à escolarização das pessoas com deficiência, a partir do indicador matrícula, nas escolas públicas das redes de ensino de Marabá-Pará, no período de 2015 a 2017 . Tem sua abordagem pautada na pesquisa qualitativa, com estudo teórico e análise documental. Dentre os resultados do estudo, é possível afirmar que, no período investigado, há dados de matrícula que indicam o acesso escolar de alunos com deficiência no Brasil, no estado do Pará e em Marabá, mas que, sobretudo, ingressam na escolarização as pessoas oriundas das camadas sociais mais favorecidas economicamente. Aponta ainda que, mesmo com um quantitativo significativo de acesso por meio da matrícula escolar, no município de Marabá, ainda encontram-se sujeitos fora da escola. Observa-se que, dentre os matriculados, muitos não tiveram acesso às salas de $A E E$, e ainda há necessidade de atenção para as peculiaridades das escolas do campo quanto à educação especial; e, de modo geral, as condições de vida econômica e social das pessoas com deficiência refletem-se no processo de acesso e permanência na escolarização desses sujeitos educacionais.

Palavras-chave: Educação Especial; acesso escolar; matrícula escolar.

\section{ABSTRACT}

This article analyzes the access to schooling for people with disabilities in the municipality of Marabá (PA), based on the indicator enrollment in special education, in public schools in the education networks, in the period from 2015 to 2017, within the context of State reform and the contradictions of the capitalist system. It is a theoretical study with a qualitative 
perspective and documentary analysis. As a result, we found that people with disabilities, from the most economically favored social strata, have access to school in Marabá, and that there is still a significant number of subjects outside school. In addition, many students enrolled in Marabá did not have access to the Specialized Educational Service rooms. Finally, we identified that rural schools still need attention regarding special education and, in general, the conditions of economic and social life of people with disabilities are reflected in the process of access and permanence in the education of these educational subjects. Keywords: Special Education; school access; school enrollment.

\section{RESUMEN}

Este artículo investiga el acceso a la escolarización de las personas con discapacidad en el municipio de Marabá (PA), con base en el indicador de matrícula en educación especial, en las escuelas públicas de las redes educativas, en el período 2015 a 2017, en el contexto de la reforma del Estado. y las contradicciones del sistema capitalista. Es un estudio teórico con perspectiva cualitativa y análisis documental. Como resultado, encontramos que las personas con discapacidad, de los estratos sociales más favorecidos económicamente, tienen acceso a la escuela en Marabá, y que todavía hay un número significativo de asignaturas fuera de la escuela. Además, muchos estudiantes matriculados en Marabá no tenían acceso a las salas del Servicio Educativo Especializado. Finalmente, identificamos que las escuelas rurales aún necesitan atención en materia de educación especial y, en general, las condiciones de vida económica y social de las personas con discapacidad se reflejan en el proceso de acceso y permanencia en la educación de estas materias educativas.

Palabras clave: Educación Especial; acceso escolar; matrícula escolar.

\section{Introdução}

A inclusão escolar é um processo que requer o acesso e a permanência dos alunos em um percurso de ensino-aprendizagem com qualidade. Mas, para isso, é imprescindível que ocorra a matrícula dos discentes e que o Estado assuma essa responsabilidade, juntamente com a família e com a sociedade em geral.

No Brasil, sobretudo nas últimas décadas, em meio a estudos e debates políticos educacionais, foi instituído um arcabouço legal com vistas a respaldar o processo de inclusão escolar das pessoas com deficiência. Desse modo, o acesso e a permanência em uma escolarização de qualidade são direitos desses sujeitos para obterem sucesso ao longo de sua formação.

Nesse contexto, um importante indicador do acesso à educação formal é a matrícula escolar, que, segundo a meta 4 do Plano Nacional de Educação-PNE (2014-2024), constitui um parâmetro de universalização do acesso à educação básica e ao Atendimento 
Educacional Especializado (AEE) (marcado como prioridade, preferencialmente, na rede comum de ensino) para as pessoas com deficiência, desde os 4 até os 17 anos de idade.

Este artigo tem como objetivo analisar $O$ acesso das pessoas com deficiência às escolas públicas das redes de ensino em Marabá (PA), considerando os dados da matrícula escolar, no período de 2015 a 2017. Nessa direção, o problema central deste estudo é norteado pela seguinte questão: $\mathrm{Em}$ que medida as pessoas com deficiência foram inseridas nas escolas públicas, em Marabá (PA), no período de 2015 a 2017 ?

Trata-se de um recorte da investigação concluída no ano de 2019, na linha de pesquisa políticas públicas educacionais do Mestrado Acadêmico do Programa de PósGraduação em Educação, da Universidade Federal do Pará, sobre a configuração da educação especial no município de Marabá. Esse município, lócus da investigação, está localizado na região sudeste paraense ${ }^{1}$ e possui uma população estimada de 275.086 pessoas, com taxa de escolarização, de 6 a 14 anos, de 94,7\%. O Índice de Desenvolvimento da Educação Básica (IDEB) para os anos iniciais, em 2017, foi de 4,6 acima da meta projetada 4,4 e os anos finais do ensino fundamental de 3,8 abaixo da meta projetada 4,6 (INEP, 2017).

A delimitação temporal considerou a série histórica de 2015 até 2017. Essa opção deu-se devido à promulgação da Lei № 13.146/2015 - Lei Brasileira de Inclusão da Pessoa com Deficiência (Estatuto da Pessoa com Deficiência) (BRASIL, 2015) até o ano de 2017.

Nessa pesquisa de cunho qualitativo, realizamos um levantamento bibliográfico para o estudo teórico que fundamenta a análise de documentos como leis, resoluções, portarias, decretos e relatórios acerca da educação especial em âmbito federal. Os dados educacionais, referentes ao quantitativo de matrículas, foram obtidos junto à base de dados do Censo Escolar, do Portal do Instituto Nacional de Estudos e Pesquisa Educacional Anísio Teixeira (INEP), Portarias Interministeriais, do Portal do Fundo Nacional de Desenvolvimento da Educação (FNDE) e os socioeconômicos, advindos do portal eletrônico do Instituto Brasileiro de Geografia e Estatística (IBGE).

Estruturalmente, no primeiro momento, discorremos sobre apontamentos teóricos conceituais acerca da pessoa com deficiência e inclusão social na sociedade capitalista; enquanto que, no segundo momento, centramos o foco no direito à educação das pessoas com deficiência fundamentado no arcabouço legal, emanado pelo Estado, nas últimas décadas; na terceira parte, analisamos os dados sobre o acesso de alunos com deficiência 
http://dx.doi.org/10.5902/1984686X48011

em escolas públicas marabaenses, a partir da matrícula escolar; e, por fim, tecemos nossas considerações finais.

\section{A pessoa com deficiência na sociedade capitalista}

Ao discorrermos teoricamente acerca da pessoa com deficiência, partimos do entendimento de que esse sujeito está situado em um contexto demarcado pela produção capitalista, que é fundamentado nas relações das forças produtivas e que gera a discrepância econômica entre as classes sociais, características estas que vêm marcando a sua existência.

Nesse sentido, consideramos o impedimento orgânico do corpo e da deficiência em um contexto marcado pelo modo de produção capitalista, a partir de um campo de discussão política iniciada pelas Upias², que considera a definição de lesão da seguinte forma:

Lesão: ausência parcial ou total de um membro, ou organismo ou mecanismo corporal defeituoso; deficiência: desvantagem ou restrição de atividade provocada pela organização social contemporânea, que pouco ou nada considera aqueles que possuem lesões físicas e os exclui das principais atividades da vida social. (DINIZ, 2007, p. 17, grifo nosso).

Compreendemos desse modo que, em uma sociedade marcada pelo consumo e por diversos tipos de apologias voltadas para aparência do corpo, a pessoa com deficiência sofre duplamente: por ter limitações corpóreas ou mentais e por estar inclusa na classe proletária. De tal modo, afirmamos que o pauperismo vem conduzindo historicamente as condições materiais desses sujeitos e se reflete no processo de inclusão/exclusão social. Neste sentido, Maior (2017, p. 30) enfatiza que:

A presença de diferenças entre os seres humanos tem sido, por séculos,
motivo de eliminação, exclusão e formas diversas de segregação das
pessoas com deficiência, tomadas como risco à sociedade, como doentes e
como incapazes. Em todas essas situações manifesta-se a opressão
daqueles que detêm o poder sobre os indivíduos em situação de
vulnerabilidade. Da invisibilidade à convivência social, houve longa trajetória
representada pelas medidas caritativas e assistencialistas, que mantiveram
as pessoas com deficiência isoladas nos espaços da família ou em
instituições de confinamento.

Estudos, discussões e lutas políticas em prol de um processo educacional includente, em um cenário contraditório marcado pelo capital, têm contribuído para que as pessoas com deficiência saiam da situação de invisibilidade e adentrem em um processo que prime pela igualdade social. Nessa direção, teorizações, ações diversificadas, políticas 
http://dx.doi.org/10.5902/1984686X48011

educacionais, dentre outros, vêm sendo criadas para superar o foco assistencialista direcionado para essa parcela da sociedade, pois não basta reconhecer a existência dos sujeitos com deficiência, mas é necessário, sobretudo, incluí-los na vida em sociedade, o que perpassa também pelo acesso à escolarização.

Cabe mencionar que esses sujeitos estão situados historicamente em uma sociedade cujo foco principal é o mercado. Segundo Maior (2017), isso contribui para a mensuração das pessoas diante do valor de troca, sobretudo quando relaciona o corpo à força de trabalho na lógica do produtivismo, o que eleva a reprodução da miséria humana da sociedade classista e excludente.

De outro modo, na história da sociedade, em sua movimentação dialética, existem várias formas de manifestações e lutas em prol de direitos e que, em menor ou maior grau, incorporam a pauta da educação inclusiva e que envolvem a educação especial.

Diante dessa abordagem, é mister estabelecermos a definição entre a educação inclusiva e educação especial. Em alguns casos, são dois âmbitos que se entrelaçam como aponta Camargo (2017, p. 2), ao dizer que:

\begin{abstract}
Há aqui outro ponto controverso, a diferença entre a educação inclusiva e a educação especial, quase sempre tomadas como sinônimos. Uma questão de pano de fundo nos é imposta: quais são os estudantes foco da educação inclusiva? A resposta é: todos. Quer dizer, ela se estende aos alunos, públicoalvo da educação especial [...] e aqueles que não são público-alvo dessa modalidade de ensino: os alunos brancos, negros, de distintos gêneros, índios, homossexuais, heterossexuais etc. ou seja, aos seres humanos reais, com foco prioritário aos excluídos do processo educacional. De forma contraditória, a cultural atual, principalmente ocidental, tenta moldá-los e "formá-los" como seres homogêneos. Como consequência, os que não se enquadram nos referidos padrões e segundo as regras de normalização forjadas socialmente, recebem vários adjetivos: 'anormais', "deficientes", "incapazes", "inválidos" etc.
\end{abstract}

Em meio às contradições do sistema capitalista, Camargo (2017) afirma que há uma tendência de excluir o diferente, sendo o nível/capacidade de produção um dos termômetros balizadores entre os mais capazes e os incapazes. Evidencia-se, assim, a opressão da lógica economicista e produtivista sobre as pessoas em situação de vulnerabilidade, marcadas como diferentes e, portanto, aptas à exclusão social e de modo específico, à exclusão escolar.

No Brasil, país demarcado por um desenvolvimento político-econômico baseado na exclusão social da maioria da população, as condições materiais das pessoas com deficiência destacam-se como questão preocupante, diante do que se prima pela defesa de uma educação inclusiva como questão central na luta dos educadores, sobretudo 
http://dx.doi.org/10.5902/1984686X48011

daqueles que vivenciam a falta de estrutura e condições adequadas de acesso e permanência nas escolas.

Nessa direção, são reivindicadas a institucionalização e a materialização de políticas públicas voltadas para a inclusão escolar das pessoas com deficiência, uma vez que:

\begin{abstract}
A deficiência é, hoje, uma questão central aos debates sobre o justo por pelo menos três razões. A primeira é que uma parcela expressiva das pessoas com deficiência é ameaçada em um dos direitos mais fundamentais à existência, o direito a estar no mundo. Essa experiência de solidão e de afastamento da vida social é resultado de ambientes pouco sensíveis aos impedimentos corporais. Deficiência não é um conceito neutro que descreve corpos com impedimentos, mas o resultado da interação do corpo com impedimentos com ambientes, práticas e valores discriminatórios. (MEDEIROS et al., 2010, p. 13, grifos dos autores).
\end{abstract}

É importante destacar que se utiliza o adjetivo deficiência para as pessoas com algum impedimento orgânico de modo geral. Esse adjetivo possui diferentes sentidos, que se desdobram em práticas sociais distintas. Sobre isso, Diniz (2007, p. 102) menciona que:

A deficiência já foi tida como um drama pessoal ou familiar, com explicações religiosas que a aproximaram ora do infortúnio, ora da benção divina em quase todas as sociedades. A contestação da narrativa mística e religiosa pela narrativa biomédica foi recebida como um passo importante para a garantia de igualdade. As causas dos impedimentos não estariam no pecado, na culpa ou no azar, mas na genética, na embriologia, nas doenças degenerativas, nos acidentes de trânsito ou no envelhecimento.

A definição conceitual de deficiência não é neutra, mas é marcada pelo modo como é pensado o corpo com impedimento, seja como uma condição biológica de existência seja pela redefinição do significado do corpo, em virtude da desvantagem provocada nas relações sociais e também da ordem ideológica de normalidade. Diante do padrão de corpo perfeito, ditado ideologicamente pela sociedade do consumo, há a classificação e inferiorização das pessoas que não se enquadram no padrão de produtividade e de independência para viver em sociedade.

A legislação educacional, com ênfase na educação especial, ao ser instituída, deve sinalizar para a inclusão das pessoas com deficiência e, com isso, contribuir para a superação da visão preconceituosa e discriminatória sobre o corpo. Sob a perspectiva do mercado, o corpo relaciona-se à capacidade de consumir e gerar mais capital, por meio da força de trabalho que ele representa.

Portanto, é necessário compreender o debate conceitual sobre a questão da deficiência, no que se refere à ótica do impedimento orgânico, sobretudo porque, nas últimas décadas, o Estado brasileiro vem regulamentando a educação especial por meio 
http://dx.doi.org/10.5902/1984686X48011

de um arcabouço legal que envolve as diferentes redes de ensino e os diversos aspectos necessários ao acesso e à permanência de seu público-alvo: as pessoas com deficiência. Nessa perspectiva, a legislação vem apontando a escolarização como um direito desses sujeitos educacionais, sobre o que discorremos no item a seguir.

\section{O direito à escolarização das pessoas deficientes}

A conjuntura econômica globalizada vem reconfigurando, nas últimas décadas, a atuação do poder público em prol de uma governabilidade intermediada pelo interesse da lógica neoliberal. Nesse sentido, em países como o Brasil, vêm ocorrendo reformas no âmbito do Estado neoliberal com foco no alargamento do mercado e com restrições para as políticas sociais, dentre as quais as educacionais. Assim, as políticas sociais, de acordo com Simionato (2000), ficaram subordinadas como medidas de restrição de custos e de focalização de ações governamentais em segmentos mais precários e de serviços básicos.

A escolarização das pessoas com deficiência vem sustentando-se sob uma ótica contraditória que, por vezes, ocorre com o constante encaixe da inclusão pela exclusão concernente ao modo de produção capitalista, sendo vista, dentro e fora da escola, com o encontro e o desencontro do ensino comum e do AEE.

Observa-se que, em meio às ideias de desenvolvimento e modernização da educação, foi instituído arcabouço legal e normativo com vistas ao acesso à educação básica pelas pessoas com deficiência, resultado dos movimentos de educadores, pesquisadores, organizações sociais e também de políticos comprometidos que lutam pela inclusão social. Assim, o tema da inclusão escolar e social das pessoas com deficiência tem, a partir de 1990, maior destaque na legislação educacional e isso tem contribuído para exigir o alargamento do acesso desses sujeitos ao processo de escolarização.

É necessário ressaltar que, a partir dos documentos e dos eventos internacionais, os processos de escolarização das pessoas com deficiência tomam maior repercussão no mundo, especialmente com a Declaração de Salamanca, do ano de 1994, que incorporou o compromisso com a universalização da educação básica, sendo necessária a implementação de políticas de acesso e permanência na escola como obrigação do Estado.

Para garantia do acesso das pessoas com deficiência ao sistema de ensino, foram criados documentos legais e normativos para a organização da escolarização. Como marco histórico, na educação brasileira, há a promulgação da segunda Lei de Diretrizes e Bases 
http://dx.doi.org/10.5902/1984686X48011

da Educação Nacional (LDB) № 9.394, de 20 de dezembro de 1996, que reconheceu a educação especial como uma modalidade de ensino:

Art. 58. Entende-se por educação especial, para os efeitos desta lei, a modalidade de educação escolar oferecida preferencialmente na rede regular de ensino, para educandos com deficiência, transtornos globais do desenvolvimento e altas habilidades ou superdotação.

$\S 1$ ํo Haverá, quando necessário, serviços de apoio especializado, na escola regular, para atender às peculiaridades da clientela de educação especial.

$\S 2^{\circ} \mathrm{O}$ atendimento educacional será feito em classes, escolas ou serviços especializados, sempre que, em função das condições específicas dos alunos, não for possível a sua integração nas classes comuns de ensino regular.

$\S 3^{\circ}$ A oferta de educação especial, dever constitucional do Estado, tem início na faixa etária de 0 (zero) a 6 (seis) anos, durante a educação infantil. (BRASIL, 1996, com redação dada pela Lei no 12.796/2013).

Desse modo, assegurou-se a educação como obrigatória (quando na faixa etária prevista) e gratuita para pessoas com deficiência e a sua oferta um dever do Estado. Destaca-se que a oferta do AEE estava acompanhada do termo preferencialmente, que delimitava as questões que envolvem as especificidades dos alunos com deficiência, os quais poderiam ser atendidos tanto no âmbito público quanto privado.

Segundo Mendes e Malheiro (2012), na LDB, os termos "educação especial", "atendimento educacional especializado" e "serviços de apoio especializado" surgem como sinônimos, o que, segundo os autores, possibilita que os alunos com deficiência continuem sendo alvo de permanente disputa da política de assistencialismo, demandado pela filantropia e pelo deslocamento do uso dos recursos do fundo público, em virtude da ausência de atendimento da escola pública e gratuita.

Segundo Garcia (2016), essa política estava articulada com as reformas neoliberais em vigência e apresentavam-se de maneira focalizada como a gestão da pobreza, da privatização na educação e da participação indireta da oferta da educação ao setor privado, bem como na formulação ideológica e pragmática de uma pedagogia do capital para a escola pública brasileira.

Nessa perspectiva, até o final da década de 1990, ocorreram poucas mudanças no que tange às práticas de integração existentes, porém, com o advento das ideias inclusivas que seguiam em curso, o debate sobre a escolarização das pessoas com deficiência foi reanimado, já que ele ocorreu inicialmente apenas como retórica, ao ser incorporado nos marcos legais e normativos. 
http://dx.doi.org/10.5902/1984686X48011

Em 2000, ocorreu a institucionalização da Política Nacional de Educação Especial, na Perspectiva Inclusiva e da definição do AEE, que foi implantado como uma prática de atividade educacional de complementação ou suplementação voltada às especificidades dos alunos com deficiência e com execução em padrão único na Sala de Recursos Multifuncionais (SRM), conforme a Resolução № 04, de 2 de outubro de 2009, que instituiu as Diretrizes Operacionais para o AEE na educação básica (BRASIL, 2009a).

Nesse ínterim, ressaltamos que o acesso à educação para as pessoas com deficiência tem respaldos legais na Política Nacional de Educação Especial - na perspectiva Inclusiva - e nas determinações da Resolução № 04/2009 e do Decreto № 7.611/2011, que asseguram a matrícula no ensino comum e no AEE para todos os alunos com deficiência (BRASIL, 2009a; 2011).

Esses documentos indicam ainda o que concerne à permanência dos alunos na escolarização, que os espaços das SRM tenham equipamentos, mobília e recursos didáticos e pedagógicos para atender à especificidade dos alunos com deficiência, mediante a complementação ou a suplementação. Portanto, ao considerar as garantias legais, caso a escolarização não seja concretizada, ocorrerá a violação de direitos e a negação de acesso à educação.

Outro importante documento é a Resolução no 02, de 11 de setembro de 2001, que estabeleceu as Diretrizes Nacionais para Educação Especial na Educação Básica. Assim, foram estabelecidos fatores determinantes a serem seguidos pelos sistemas de ensino com a responsabilidade pela promoção de organização de infraestrutura para que acontecesse o atendimento educacional e as condições necessárias para o ensino.

Nesse sentido, o Artigo 3ํ da Resolução № 02/2001 salienta que:

Art. $3^{\circ}$ Por educação especial, modalidade da educação escolar, entende-se
um processo educacional definido por uma proposta pedagógica que
assegure recursos e serviços educacionais especiais, organizados
institucionalmente para apoiar, complementar, suplementar e, em alguns
casos, substituir os serviços educacionais comuns, de modo a garantir a
educação escolar e promover o desenvolvimento das potencialidades dos
educandos que apresentam necessidades educacionais especiais, em todas
as etapas e modalidades da educação básica.

Parágrafo único. Os sistemas de ensino devem constituir e fazer funcionar um setor responsável pela educação especial, dotado de recursos humanos, materiais e financeiros que viabilizem e deem sustentação ao processo de construção da educação inclusiva. (BRASIL, 2001, p. 1).

O arcabouço legal e normativo trazia a possibilidade da criação de classes especiais para alunos com deficiência, mas vinha com a concepção de inclusão escolar e provocava 
http://dx.doi.org/10.5902/1984686X48011

conflito de interesse por meio do discurso ideológico de humanização capitalista. Contraditoriamente, partia da condição excludente e articulava a escolarização dos alunos com deficiência à capacitação para o mundo do trabalho.

Em relação ao acesso das pessoas com deficiência nas escolas, o Decreto № 6.949, de 25 de agosto de 2009, trouxe a reafirmação da matrícula dos alunos, indicando que nenhuma pessoa com deficiência poderia ser rejeitada sob a proteção da existência de um sistema educacional inclusivo, em todos os níveis de ensino, e, dentre outras garantias, na busca de oportunidades igualitárias, a eliminação das barreiras sociais e o combate à discriminação (BRASIL, 2009b).

Esse Decreto faz parte do processo de ratificação da Convenção Internacional dos Direitos das Pessoas com Deficiência. No Brasil, esse documento assumiu um status de emenda constitucional e, segundo Barbosa (2015), ele apresenta-se como uma lógica universalista das sociedades contemporâneas e necessidade de justiça e que "pretende intervir em sistemas de proteção já construídos, provando muito mais mudanças de orientação do que de fundamentação" (BARBOSA, 2015, p. 81-82).

Nessa mesma perspectiva, foi instituída a Lei № 13.146, de 6 de julho de 2015:

Art. 1ํ É instituída a Lei Brasileira de Inclusão da Pessoa com Deficiência (Estatuto da Pessoa com Deficiência), destinada a assegurar e a promover, em condições de igualdade, o exercício dos direitos e das liberdades fundamentais por pessoa com deficiência, visando à sua inclusão social e cidadania $[\ldots]$

Art. $4^{\circ}$ Toda pessoa com deficiência tem direito à igualdade de oportunidades com as demais pessoas e não sofrerá nenhuma espécie de discriminação [...]

Art. 5 $\mathrm{A}$ pessoa com deficiência será protegida de toda forma de negligência, discriminação, exploração, violência, tortura, crueldade, opressão e tratamento desumano ou degradante [...]

Art. 27. A educação constitui direito da pessoa com deficiência, assegurado sistema educacional inclusivo em todos os níveis e aprendizado ao longo de toda a vida, de forma a alcançar o máximo desenvolvimento possível de seus talentos e habilidades físicas, sensoriais, intelectuais e sociais, segundo suas características, interesses e necessidades de aprendizagem.

Parágrafo único. É dever do Estado, da família, da comunidade escolar e da sociedade assegurar educação de qualidade à pessoa com deficiência, colocando-a a salvo de toda forma de violência, negligência e discriminação. (BRASIL, 2015).

Essa Lei afirma a garantia de igualdade e pleno exercício dos direitos, especialmente na área educacional; reconhece a inclusão escolar e reforça a incumbência do poder público em atender às necessidades educacionais, mediante um aprimoramento que assegure o acesso, a permanência, a participação e a aprendizagem ao longo de toda a 
vida. Garantias estas que podem ocorrer por meio da oferta de serviços e de recursos de acessibilidade, que eliminem as barreiras e promovam a inclusão plena dos sujeitos.

Na próxima seção, apresentamos e analisamos dados acerca da matrícula escolar no lócus da pesquisa.

\section{A matrícula na educação especial, em Marabá, no período 2015 a 2017}

Ao analisarmos o acesso escolar das pessoas com deficiência, faz-se necessário levantar aspectos que interferem nesse processo, como as condições materiais necessárias à existência desses sujeitos. Tratando-se da renda domiciliar per capita, os dados do relatório do $2^{\circ}$ Ciclo de Monitoramento do PNE de 2018 indicam esse aspecto, conforme o gráfico 1.

Gráfico 1 - Percentual das pessoas com deficiência na faixa etária de 4 a 17 anos com frequência escolar conforme a renda domiciliar per capita, no Brasil

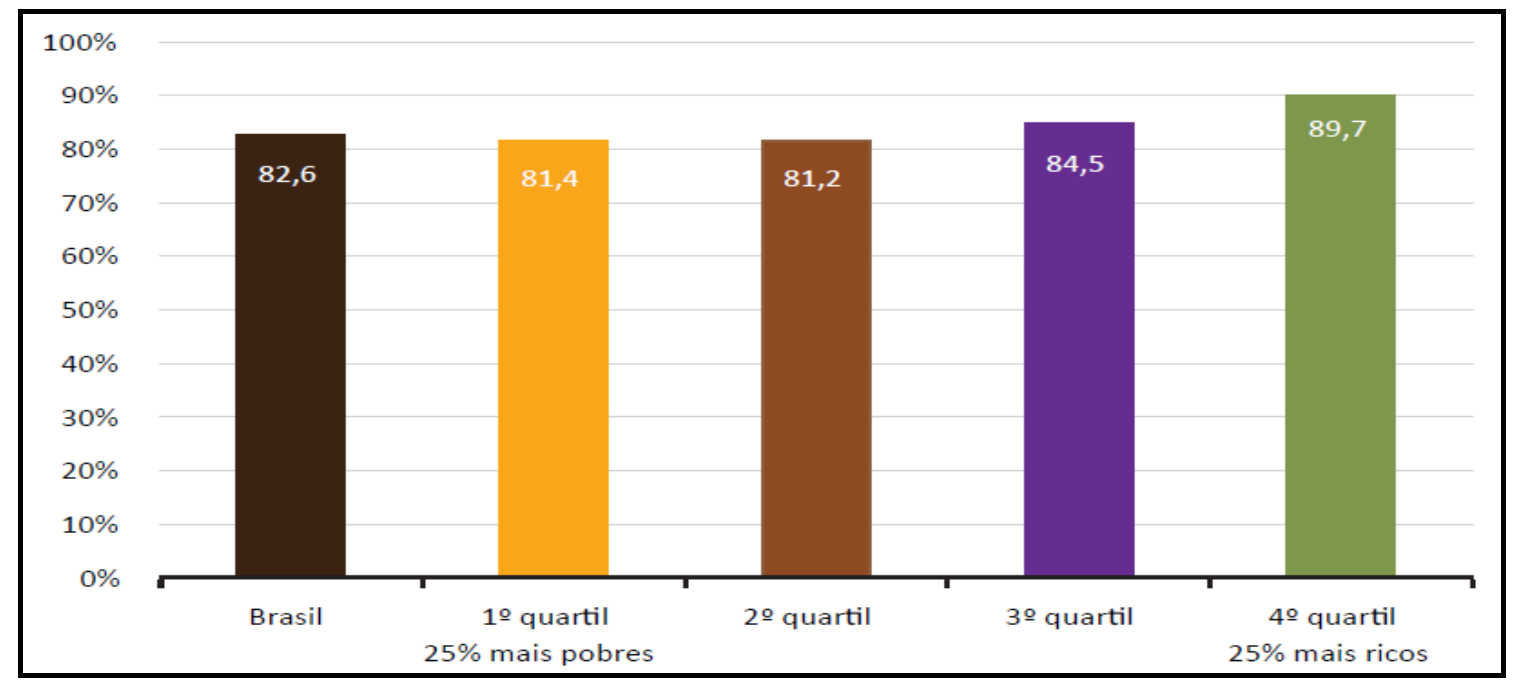

Fonte: Elaborado por Dired/Inep com base em dados do Censo Demográfico 2010/IBGE (2010).

A partir desses dados, é possível constatar que a renda per capita tem uma implicação direta com a escolarização das pessoas com deficiência na faixa etária de ensino obrigatório, uma vez que ela intervém no acesso à escola. Ressalta-se que a maior proporção do percentual de frequência foi a dos alunos com deficiência possuidores de renda mais elevada, sendo o total de $89,7 \%$ dos mais ricos; enquanto que, entre os mais pobres, o percentual foi de $81,4 \%$, estabelecendo-se uma diferença de percentual em $8,3 \%$ a menos (BRASIL, 2018).

Como resultados de evolução de matrículas alcançadas, o relatório do $2^{\circ}$ Ciclo de Monitoramento do PNE de 2018 mencionou que, no ano de 2017, os percentuais de acesso 
às classes de ensino comum, referentes aos alunos com deficiência, foram ampliados em nível nacional em todas as redes de ensino, tendo um alcance de $97,4 \%$, nas estaduais, $96,6 \%$, nas municipais, $82,1 \%$, nas federais, e $47,6 \%$, nas privadas.

A tabela 1 evidencia o quantitativo de matrícula dos alunos com deficiência, por rede de ensino (estadual e municipal) do país, do estado e do município pesquisado, no período de 2015 a 2017.

Tabela 1 - Matrículas da educação especial nas redes de ensino público estadual e municipal, no Brasil, no Pará e em Marabá, nos anos de 2015 até 2017

\begin{tabular}{cccccccc}
\hline \multirow{2}{*}{ Ano } & \multicolumn{2}{c}{ BRASIL (A) } & \multicolumn{2}{c}{ PARÁ (B) } & \multicolumn{2}{c}{ MARABÁ (C) } & Total \\
& Estadual & Municipal & Estadual & Municipal & Estadual & Municipal & $(\mathbf{A + B +})$ \\
\hline 2015 & 253.693 & 491.670 & 4.704 & 25.352 & 32 & 1.027 & 776.478 \\
2016 & 266.148 & 518.160 & 5.629 & 26.246 & 60 & 1.002 & 817.245 \\
2017 & 304.311 & 573.326 & 7.102 & 30.148 & 53 & 1.108 & 916.048 \\
\hline $\begin{array}{c}\% \mathbf{\Delta} \\
\mathbf{2 0 1 5 / 2 0 1 7}\end{array}$ & $\mathbf{1 9 , 9 5}$ & $\mathbf{1 6 , 6 1}$ & $\mathbf{5 0 , 9 8}$ & $\mathbf{1 8 , 9 2}$ & $\mathbf{6 5 , 6 3}$ & $\mathbf{7 , 8 9}$ & $\mathbf{1 7 , 9 7}$ \\
\hline
\end{tabular}

Fonte: Elaboração própria das autoras com base nos dados do INEP/Censo Escolar/Resultados e Resumos/Anexo II (2015-2017).

Os dados indicam que permaneceu uma dinâmica de ampliação de matrículas no território nacional. No decorrer da série histórica, o número de matrículas do público participante da educação especial vem mantendo-se em um crescimento constante nos níveis nacional, estadual e municipal. Também observamos que a rede municipal é a responsável pelo maior número de matrículas dos alunos com deficiência.

O gráfico 2 apresenta o índice de crescimento da rede estadual e municipal, durante a série histórica.

Gráfico 2 - Percentual de crescimento do número de matrículas nas redes de ensino público estadual e municipal no Brasil, no Pará e em Marabá, nos anos de 2015 até 2017

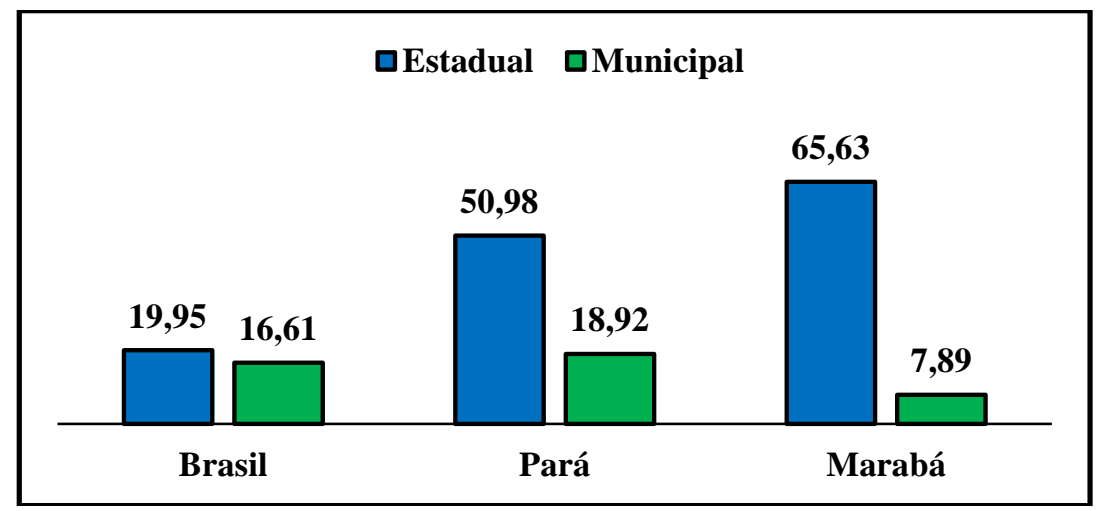

Fonte: Elaboração própria com base nos dados do INEP/Censo Escolar/Resultados e Resumos/Anexo II (2015-2017). 
Pode-se inferir que houve um crescimento em todos os anos, o que resultou em um índice percentual de $17,97 \%$ do total geral de matrículas. Em nível nacional, os dados mostram que foi de 19,95\%, na rede estadual, e 16,61\%, na rede municipal. Importante destacar que o estado do Pará apresentou o índice de 50,98\%, nas redes estaduais, e de 18,92 , nas redes municipais. No entanto, constatamos que o maior número de matrículas dos alunos com deficiência está sob a responsabilidade dos municípios.

A Rede de Ensino Estadual em Marabá obteve o percentual de 65,63\%. Esse número não expressa a realidade de maneira abrangente, pois o acréscimo representa apenas 21 matrículas, enquanto que, na Rede de Ensino Municipal, o percentual foi de 7,89\%, com o aumento de 81 matrículas de alunos com deficiência. Além disso, enfatizamos que a variação de crescimento de matrícula foi constante a cada ano, porém a Rede Estadual, em Marabá, apresentou dados oscilantes com perda em relação aos dados de matrículas do ano anterior no comparativo, entre os anos de 2016 e 2017.

$\mathrm{Na}$ tabela 02, apresentamos especificamente os dados de matrículas da Educação Especial no território brasileiro, com ênfase para o estado do Pará e para o município de Marabá, com o refinamento para zona urbana e o campo:

Tabela 2 - Detalhamento das matrículas dos alunos com deficiência nas Redes de Ensino Público Municipal, no Brasil, no Pará e em Marabá, no período 2015-2017

\begin{tabular}{|c|c|c|c|c|c|}
\hline Local & Zona & 2015 & 2016 & 2017 & $\begin{array}{c}\% \Delta \\
2015 / 2017\end{array}$ \\
\hline & $\begin{array}{c}\text { Total A } \\
(\mathrm{D}+\mathrm{G}+\mathrm{J})\end{array}$ & 518.049 & 545.408 & 604.852 & 16,76 \\
\hline \multirow{4}{*}{ BRASIL } & Urbano (B) & 406.854 & 431.916 & 479.259 & - \\
\hline & Campo (C) & 84.816 & 86.244 & 94.067 & - \\
\hline & Total D $(B+C)$ & 491.670 & 518.160 & 573.326 & 16,61 \\
\hline & $\%(D / A)$ & 94,91 & 95,00 & 94,79 & - \\
\hline \multirow{4}{*}{ PARÁ } & Urbano (E) & 17.596 & 18.474 & 21.156 & - \\
\hline & Campo (F) & 7.756 & 7.772 & 9.262 & - \\
\hline & Total G $(E+F)$ & 25.352 & 26.246 & 30.418 & 19,98 \\
\hline & $\%(\mathbf{G} / \mathbf{A})$ & 4,89 & 4,81 & 5,03 & - \\
\hline \multirow{4}{*}{ MARABÁ } & Urbano $(\mathrm{H})$ & 858 & 867 & 983 & - \\
\hline & Campo (I) & 169 & 135 & 125 & - \\
\hline & Total J $(\mathrm{H}+\mathrm{l})$ & 1.027 & 1.002 & 1.108 & 7,89 \\
\hline & $\%(\mathbf{H} / \mathbf{A})$ & 0,20 & 0,18 & 0,18 & - \\
\hline
\end{tabular}

Fonte: Elaboração própria com base nos dados do INEP/Censo Escolar/Resultados e Resumos/Anexo II (2015-2017).

Ao analisarmos os dados da Tabela 2, percebemos que, no Brasil, no Pará e em Marabá, as matrículas dos alunos com deficiência, de maneira geral, nas redes de ensino municipais, na zona urbana e no campo, tiveram aumento nos índices em cada ano, ou seja, o crescimento manteve-se constante, mesmo com pouca elevação de percentual. Há, 
contudo, uma exceção: os valores que representam o indicador referente ao campo no município de Marabá demonstraram que houve um decréscimo de aproximadamente $26,04 \%$, enquanto a zona urbana teve um aumento de $14,57 \%$.

A partir dos dados, destacamos que há uma parcela expressiva de pessoas com deficiência que vive no campo. Assim, resulta também o crescente número de matrículas. Vale ressaltar que os dados do censo escolar não informaram se os alunos com deficiência tiveram acesso ao AEE em sala de recursos multifuncionais ou instituições especializadas, sendo esse um fator limitante para o entendimento do modo de implementação da política de educação voltada para inclusão escolar desses alunos.

Segundo Caiado et al (2016), os percentuais de 16,28\% das pessoas com deficiência que vivem no campo correspondem ao total de 8,9\% dessa população. Os autores ainda apontam que existe uma escassez de produção na área da educação especial que aborde a especificidade cultural dessas pessoas e isso tem provocado a invisibilidade desses sujeitos. Os autores também se referem a questões que precisam de discussão sobre as escolas do campo, de maneira que a realidade possa ser conhecida e traga possibilidade de formulação e implementação de propostas educacionais.

Para melhor compreensão sobre o processo de acesso à escolarização dos alunos com deficiência na Rede de Ensino Municipal de Marabá, apresentamos a tabela 3 com detalhamento de dados por distribuição, localização, etapas e modalidade de ensino.

Tabela 3 - Detalhamentos das matrículas dos alunos com deficiência por localização, etapas e modalidade de ensino na rede municipal de ensino em Marabá, no período de 2015 até 2017

\begin{tabular}{|c|c|c|c|c|c|c|c|c|c|}
\hline \multirow{3}{*}{ Ano } & \multirow{3}{*}{ Local } & \multicolumn{2}{|c|}{$\begin{array}{l}\text { Educação Infantil } \\
\text { (A) }\end{array}$} & \multicolumn{4}{|c|}{ Ensino Fundamental (B) } & \multirow{3}{*}{$\begin{array}{c}\text { EJA (C) } \\
\text { Fundamental } \\
\text { Presencial }\end{array}$} & \multirow{3}{*}{$\begin{array}{c}\text { Total } \\
(\mathrm{A}+\mathrm{B}+\mathrm{C})\end{array}$} \\
\hline & & \multirow{2}{*}{$\begin{array}{l}\text { Creche } \\
\text { Parcial }\end{array}$} & \multirow{2}{*}{$\begin{array}{l}\text { Pré-escola } \\
\text { Parcial }\end{array}$} & \multicolumn{2}{|c|}{ Anos Iniciais } & \multicolumn{2}{|c|}{ Anos Finais } & & \\
\hline & & & & Parcial & Integral & Parcial & Integral & & \\
\hline \multirow{2}{*}{2015} & Urbana & 03 & 45 & 451 & 41 & 220 & 31 & 67 & 1.027 \\
\hline & Campo & - & 03 & 92 & 24 & 34 & 10 & 06 & \\
\hline \multirow{2}{*}{2016} & Urbana & 13 & 39 & 454 & 19 & 265 & 10 & 67 & 1.002 \\
\hline & Campo & 0 & 05 & 86 & 04 & 36 & 0 & 04 & \\
\hline \multirow{2}{*}{2017} & Urbana & 11 & 51 & 501 & 53 & 279 & 32 & 56 & 1.108 \\
\hline & Campo & - & 03 & 86 & 11 & 20 & 01 & 04 & \\
\hline
\end{tabular}

Fonte: Elaboração própria com base nos dados do INEP/Censo Escolar/Resultados e Resumos/Anexo II (2015-2017).

Os dados indicam que as médias percentuais de matrículas correspondem à seguinte distribuição: o total de 5,61\% na educação infantil; 58,08\% no Ensino Fundamental - anos iniciais; com 29,90\% no Ensino Fundamental - anos finais; e 6,50\% na Educação de Jovens 
e Adultos. De tal modo, a maioria das matrículas está no Ensino Fundamental inicial, principalmente na condição de parcial.

Ao mensurar as matrículas agregadas com os valores de parcial e integral, tanto para localização urbana quanto para o campo, estas corresponderam aproximadamente com o percentual de 59,20\%, no ano de 2015. Em relação ao ano de 2016, houve um decréscimo com a redução para 56,19\%, mas novamente torna a aumentar para 58,75\%, em 2017. Ao observarmos o conjunto dos resultados, constatamos um aumento de ordem progressiva para a zona urbana e para o campo com variação percentual de 7,89\%, na série histórica.

Os dados da tabela 4 têm como referência as portarias interministeriais. Esses documentos divulgam as matrículas do censo escolar para base do cálculo estimado da receita anual do FUNDEB, e permitem que sejam observadas as matrículas desagregadas em relação ao cômputo da duplicidade.

Tabela 4 - Matrículas dos alunos com deficiência no ensino comum e atendimento educacional especializado como referência para base do cálculo da receita do FUNDEB, em Marabá, período de 2015 a 2017

\begin{tabular}{cccccc}
\hline \multirow{2}{*}{ Ano } & \multicolumn{3}{c}{ Número de Matrículas } & \multicolumn{2}{c}{$\% \mathbf{\Delta}$} \\
\cline { 2 - 6 } & $\begin{array}{c}\text { Ensino } \\
\text { Comum (A) }\end{array}$ & $\begin{array}{c}\text { Atendimento } \\
\text { Educacional } \\
\text { Especializado (B) }\end{array}$ & Total (C) & (A/C) & (B/C) \\
\hline 2015 & 855 & 400 & $\mathbf{1 2 5 5}$ & 68,13 & 31,87 \\
2016 & 921 & 483 & $\mathbf{1 4 0 4}$ & 65,60 & 34,40 \\
2017 & 969 & 504 & $\mathbf{1 4 7 3}$ & 65,78 & 34,22 \\
\hline$\% \mathbf{2 0 1 5 / 2 0 1 7}$ & $\mathbf{1 3 , 3 3}$ & $\mathbf{2 6}$ & $\mathbf{1 7 , 3 7}$ & $\mathbf{-}$ & - \\
\hline
\end{tabular}

Fonte: Elaboração própria com base nas Portarias Interministeriais № 17/2014, № 11/2015 e № 08/2017.

Os dados da Tabela 4, que tratam das matrículas da educação especial (ensino comum) e do AEE, evidenciam que houve um crescimento ascendente com o percentual respectivo de 13,33\% e 26\%. Desse modo, o recurso financeiro destinado ao processo de escolarização dos alunos com deficiência foi ampliado conforme a política de fundos em vigência.

Ao considerar que os mesmos alunos com deficiência, os quais tiveram as matrículas computadas na educação especial (ensino comum), deveriam frequentar o AEE, houve uma discrepância dos dados, pois aproximadamente 50,36\% ficaram sem acesso ao ensino especializado. Portanto, ainda persiste, de maneira expressa, a ausência da oferta do AEE.

No comparativo entre os anos da série histórica, notamos que, no ano de 2015, apenas $46,78 \%$ dos alunos tiveram acesso ao AEE, enquanto mais da metade, ou seja, um 
http://dx.doi.org/10.5902/1984686X48011

total de 53,22\% ficou sem acesso. Esse número corresponde a 455 alunos com deficiência. No ano de 2016, a situação pouco alterou-se e o total foi de 52,44\% que tiveram dados de matrículas, enquanto que $47,56 \%$, sem acesso. Novamente o cenário negativo repete-se para 438 alunos com deficiência. Semelhantemente, no ano de 2017 , o total de $52,01 \%$ de registros de matrícula dos frequentes e $47,99 \%$, dos ausentes. Esses dados são equivalentes a 465 alunos com deficiência.

Os dados mostram que a matrícula por si só não é suficiente para um processo qualitativo de formação, mas, sobretudo, é um aspecto inicial que requer um conjunto de outros indicadores, como uma boa estrutura física, formação docente, equipamentos e materiais didáticos, dentre outros que contribuem para a inclusão escolar da pessoa com deficiência.

\section{Considerações finais}

A pesquisa sobre 0 acesso à escolarização pelas pessoas com deficiência, em Marabá (PA), possibilitou reflexões sobre a matrícula escolar e permitiu inferir que a inclusão escolar não se faz somente com matrícula, apesar de este ser um importante aspecto no processo de inserção dos alunos na educação formal. Portanto, compete ao Poder Público com o apoio da família e a sociedade em geral fomentarem instrumentos e condições necessárias para que a inclusão aconteça no cotidiano escolar e social.

Uma vez que a educação escolar e os demais direitos sociais são basilares para a formação humana, o poder público tem responsabilidade, juntamente com a sociedade, pela materialidade de políticas públicas que criem as condições necessárias para que os sujeitos com deficiência sejam bem-sucedidos na vida escolar, tendo suas necessidades atendidas.

A política nacional focalizada nos alunos com deficiência é constituída por um emaranhado conceitual e amparada na legislação, como a Convenção dos Direitos das Pessoas com Deficiência e a Lei Brasileira de Inclusão № 13.146/2015 (BRASIL, 2015), um documento que regulamenta a garantia ao direito à educação e aponta a necessidade $e$ obrigatoriedade do sistema educacional em todos os níveis, e de aprendizado ao longo da vida das pessoas com deficiência.

O fundamento legal para a garantia do direito à educação e ao convívio social vislumbra uma escola inclusiva que contribua para a superação da exclusão dos sujeitos com deficiência e tidos como menos capazes à sociedade capitalista. Neste sentido, há 
http://dx.doi.org/10.5902/1984686X48011

expectativa em prol do fortalecimento da luta por condições de reconhecimento da heterogeneidade humana e valorização dos sujeitos sociais.

Isso requer a concretização de ações educacionais contra a violação e o descaso que persistem no cotidiano escolar e do distanciamento da qualidade do ensino público gratuito, a iniciar pela matrícula dos alunos com deficiência e passando pela oferta de condições para permanecerem no processo de ensino e aprendizagem com qualidade.

No estudo sobre a escolarização para os alunos com deficiência em Marabá (PA), chamam-nos a atenção três aspectos detectados em nossa pesquisa, quais sejam: a) os dados analisados indicam um crescente acesso à escolarização por meio da matrícula escolar, embora ainda existam pessoas com deficiência fora da escola; b) um quantitativo significativo de alunos, no período analisado não tiveram acesso às SRM; e, ainda destacase que c) a educação especial nas escolas do campo carece de adequação para valorizar o aspecto cultural da população.

Os desafios estão postos diante do processo de escolarização das pessoas com deficiência, a iniciar pelo acesso, que sofre influências de variados determinantes dentre os quais os aspectos social e econômico dos sujeitos educacionais, o apoio e 0 acompanhamento dos familiares e o provimento necessário para a funcionalidade da escola com qualidade pelo Poder Público.

Assim, torna-se necessário buscar a superação das carências vivenciadas cotidianamente pelos sujeitos educacionais da educação especial para que os alunos com deficiência tenham êxito no processo educacional formal, principalmente como sujeitos de direitos e inclusos na sociedade, e, desse modo, tenham seus direitos não somente garantidos legalmente, mas também concretizados.

\section{Referências}

BARBOSA, Lívia. Convenção sobre os direitos das pessoas com deficiência: avanços e desafios. In: ANJOS, Hildete Pereira. Olhando a educação como um direito: deficiência, inclusão e diversidade. Belém: Paka-Tatu, 2015.

BRASIL. Lei no 9.394, de 20 de dezembro de 1996. Estabelece as diretrizes e bases da educação nacional. Diário Oficial da União, Brasília, DF, 20 dez. 1996.

BRASIL. Resolução CNE/CEB № 2, de 11 de setembro de 2001. Institui Diretrizes Nacionais para a Educação Especial na Educação Básica. Brasília, DF, 2001. Disponível em: http://portal.mec.gov.br/cne/arquivos/pdf/CEB0201.pdf. Acesso em: 10 out. 2017. 
http://dx.doi.org/10.5902/1984686X48011

BRASIL. Resolução CNE/CEB № 4, de 2 de outubro de 2009. Institui Diretrizes Operacionais para o Atendimento Educacional Especializado na Educação Básica, modalidade Educação Especial. Brasília, DF, 2009a. Disponível em: http://portal.mec.gov.br/dmdocuments/rceb004_09.pdf. Acesso em: 05 jan. 2018.

BRASIL. Decreto № 6.949, de 25 de agosto de 2009. Promulga a convenção internacional sobre os direitos das pessoas com deficiência. Diário Oficial da União, Brasília, DF, 26 ago. 2009b. Disponível em:

http://portal.mec.gov.br/dmdocuments/decreto6949_seesp.pdf. Acesso em: 05 jan. 2018.

BRASIL. Decreto no 7.611, de 17 de novembro de 2011. Dispõe sobre a educação especial, o atendimento educacional especializado e dá outras providências. Diário Oficial da União, Brasília, DF, 18 nov. 2011. Disponível em:

http://www.mpsp.mp.br/portal/page/

portal/Educacao/Legislacao/Federal/Decreto_no_7611_171111_EducaçãoEspecial.pdf. Acesso em: 18 jul. 2018.

BRASIL. Portaria Interministerial $n^{\circ} 17$ de 29 de novembro de 2014. Matrículas da Educação Básica consideradas no FUNDEB em 2015, estimativa da receita anual do fundo e coeficientes de distribuição dos recursos por ente governamental. Brasília, DF, 2014. Disponível em: https://www.fnde.gov.br/index.php/centrais-deconteudos/publicacoes/ category/147-matriculas-da-eb-estimativa-ecoeficientes?download=9313:matricula-port-17. Acesso em: 02 fev. 2019.

BRASIL. Portaria Interministerial $n^{\circ} 11$ de 30 de dezembro de 2015. Matrículas da Educação Básica consideradas no FUNDEB em 2016, estimativa da receita anual do fundo e coeficientes de distribuição dos recursos por ente governamental. Brasília, DF, 2015. Disponível em: https://www.fnde.gov.br/index.php/centrais-deconteudos/publicacoes/ category/147-matriculas-da-eb-estimativa-ecoeficientes?download=9739:matriculas-da-eb-estimativa-e-coeficientes-2016-portaria-n11-2015-para. Acesso em: 02 fev. 2019.

BRASIL. Lei no 13.146, de 06 de julho de 2015. Lei Brasileira de Inclusão da Pessoa com Deficiência - Estatuto da pessoa com deficiência. Câmara dos Deputados. Brasília, DF: Câmara dos Deputados, Edições Câmara, 2015. Disponível em: http://www.cnmp.mp.br/portal/images/lei_brasileira_inclusao_pessoa_deficiencia.pdf. Acesso em: 26 jul. 2018.

BRASIL. Portaria Interministerial $n^{\circ} 08$ de 29 de novembro de 2017. Matrículas da Educação Básica consideradas no FUNDEB em 2017, estimativa da receita anual do fundo e coeficientes de distribuição dos recursos por ente governamental. Brasília, DF, 2017. Disponível em: https://www.fnde.gov.br/index.php/centrais-deconteudos/publicacoes/ category/54-consultas?download=11429:pa-port-interminn08-2911-17. Acesso em: 02 fev. 2019.

BRASIL. Instituto Brasileiro de Geografia e Estatística. Síntese dos Indicadores Sociais do ano de 2017. Rio de Janeiro: IBGE, 2017. Disponível em: https://agenciadenoticias. ibge.gov.br/agencia-noticias/2012-agencia-denoticias/noticias/23299-pobreza-aumenta-eatinge-54-8-milhoes-de-pessoas-em-2017. Acesso em: 26 jul. 2018. 
BRASIL. Instituto Nacional de Estudos e Pesquisas Educacionais Anísio Teixeira.

Relatório do $2^{\circ}$ Ciclo de Monitoramento das Metas do Plano Nacional de Educação 2018. Brasília, DF: Inep, 2018. Disponível em: http://portal.inep.gov.br/documents/186968/ 485745/RELAT\%C3\%93RIO+DO+SEGUNDO+CICLO+DE+MONITORAMENTO+DAS+M ETAS+DO+PNE+2018/9a039877-34a5-4e6a-bcfd-ce93936d7e60?version=1.17. Acesso em: 10 jan. 2018.

CAIADO, Katia Regina Moreno; GONÇALVES, Taísa Grasiela Gomes Liduenha; SÁ, Michele Aparecida de. Educação escolar no campo: desafios à educação especial. Linhas Críticas, Brasília, v. 22, n. 48, p. 324-345, mai./ago. 2016. Disponível em: https://periodicos.unb.br/index.php/linhascriticas/article/download/4887/4450/. Acesso em: 14 jan. 2019.

CAMARGO, Eder Pires de. Inclusão social, educação inclusiva e educação especial: enlaces e desenlaces. Ciência \& Educação, Bauru, SP, v. 23, n. 1, p. 1-6, jan./mar. 2017. Disponível em: http://www.scielo.br/pdf/ciedu/v23n1/1516-7313-ciedu-23-01-0001.pdf. Acesso em: 14 jan. 2019.

DINIZ, Débora. O que é deficiência. São Paulo: Brasiliense, 2007.

GARCIA, Rosalba Maria Cardoso. Educação especial na perspectiva inclusiva: determinantes econômicos e políticos. Revista Comunicações, Piracicaba, SP, v. 23, n. 03, número especial, p. 7-26, 2016. Disponível em: http://dx.doi.org/10.15600/2238121X/comunicacoes.v23nespp7-26. Acesso em: 15 out. 2018.

MAIOR, Izabel Maria Madeira de Loureiro. Movimento político das pessoas com deficiência: reflexões sobre a conquista de direitos. Revista Inclusão Social, Brasília, v.10 n.2, p.28-36, jan./jun. 2017. Disponível em: http://revista.ibict.br/inclusao/article/viewFile/4029/3365. Acesso em: 10 dez. 2018.

MEDEIROS, Marcelo; DINIZ, Debora; BARBOSA, Lívia Barbosa. Deficiência e igualdade: o desafio da proteção social. In: DINIZ, Debora; MEDEIROS, Marcelo; BARBOSA, Lívia Barbosa (org.). Deficiência e igualdade. Brasília, DF: Letras Livres: Editora Universidade de Brasília, 2010.

MENDES, Enicéia Gonçalves; MALHEIRO, Cícera A. Lima. Sala de recursos multifuncionais: é possível um serviço "tamanho único" de atendimento educacional especializado? In: MIRANDA, Theresinha Guimarães; GALVÃO FILHO, Teófilo Alves. 0 professor e a educação inclusiva: formação, práticas e lugares. Salvador: EDUFBA, 2012.

OLIVEIRA, Ivanilde Apoluceno de. Políticas e práticas de inclusão de pessoas com deficiência na Amazônia paraense: um olhar a partir de produções acadêmicas. In: ANJOS, Hildete Pereira dos. Olhando a educação como um direito: deficiência, inclusão e diversidade. Belém: Paka-Tatu, 2015.

SIMIONATTO, Ivete. Reforma do Estado ou modernização conservadora? Portal eletrônico Gramsci e o Brasil. Juiz de Fora, MG, 2000. Disponível em: https://www.acessa.com/gramsci/?id=56. Acesso em: 16 dez. 2017. 


\section{Notas}

$1 \mathrm{O}$ acesso a esse município paraense se dá por três rodovias, a BR-222, a BR-230 (Transamazônica) e a PA-150; conta ainda com o acesso por meio da estrada de Ferro Carajás e dispõe de estação ferroviária, além do acesso por via aérea. Possui uma extensão territorial de $15.128,058 \mathrm{~km}^{2}$. Tem o 3 을 maior Produto Interno Bruto (PIB) do estado do Pará com $R \$ 7,4$ bilhões de reais e indicadores do PIB per capita de $R \$$ $28.020,90$ (vinte e oito mil, vinte reais e noventa centavos). É o quarto município mais populoso do estado do Pará e com a densidade demográfica de 15,45 hab./km² para o ano de 2019 (IBGE, 2019).

2 A primeira organização política denominada de Liga dos Lesados Físicos Contra a Segregação (Upias), criada em 1972, sendo idealizada e gerenciada por membros com lesões físicas. O seu diferencial foi marcado pela resistência política e intelectual ao modelo médico. De tal modo, o objetivo estava pautado no questionamento sobre o entendimento da deficiência para além do resultado da lesão, mas para a questão social de opressão sobre o corpo lesionado (DINIZ, 2007).

\section{Correspondência}

Mírian Rosa Pereira - Universidade do Estado do Pará, Campus VIII - Marabá, Avenida Hiléia. Agrópolis do INCRA, Amapá, Marabá, Pará - Brasil.

CEP: $68502-100$

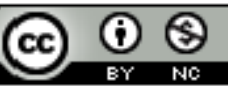

This work is licensed under a Creative Commons Attribution-NonCommercial 4.0 International (CC BY-NC 4.0) 